\title{
DIMENSIONS OF EPISTEMIC AUTHORITY OF UNIVERSITY PROFESSORS
}

\author{
SOLVEIGA BLUMBERGA' \\ Riga International School of Economics and Business Administration, Riga, Latvia
}

\begin{abstract}
The article analyses the issue of the concept of social epistemology regarding knowledge transmission from the point of view of social psychology. Knowledge transmission is related to the epistemic aspect of authority, which is demonstrated by the structural element of authority - source of knowledge or the assumed truth. In higher education, the distinction of epistemology is related to epistemological views, their multiple dimensions which show the extent and type how students perceive professors as epistemic authorities - sources of knowledge who are trusted and relied on.
\end{abstract}

\section{UDC CLASSIFICATION \& KEYWORDS}

- 165 a Epistemic beliefs - Perceived epistemic authority

\section{INTRODUCTION}

Researchers of constructive sociology of knowledge (Miettinen, Virkkunen, 2005; Subramaniam, 2010) believe that, in the contemporary knowledge society, construction of epistemic objects or cognitive objects (i.e., also social issues) is becoming more and more essential in the work of any expert. Authority of the pedagogue in the formal education processes is believed to be one of the most essential aspects of the issue of personal authority (Chiang, 2009; Kruglanski et al., 2005; Patchen, Crawford, 201; Pounder, 2008). Therefore, the concept of epistemic authority has become topical in research studies into authority. Epistemic authority is defined as a source of information having the decisive influence on the formation of knowledge, and its acknowledgement relates to the reasons for reliance on epistemic authority (Kruglanski, 1989; Kruglanski et al., 2005; Raviv, Bar- Tal, Raviv, Abin, 1993).

In social psychology, the concept of epistemic authority is researched in the context of the concept of social judgements in relation to the developing degree of epistemic dependence (Kruglanski et al., 2005; Rupp, 2011). Since epistemic authority is related to interaction in social context, a topical issue is one regarding experts and their knowledge, and a sign of epistemic authority is the degree to which claims for the role of an expert are accepted by another person (Kruglanski, 1989; Mugny, Chatard, Quiamzade, 2006, Quiamzade, Mugny, Chatard, 2009). Therefore, researchers turn to exploration of social views, beliefs (they are also defined as epistemological) (Bar-Tal et al., 1991), and such research is associated with an explanation of perception and interpretation of information (Ward, Parr, 2006); influence of epistemic authority at university (Guimond, 2001). The concept of epistemic authority is related to subjective belief which determines the attitude towards the source of information.

\section{Methodology}

The methodological basis of the epistemic authority studies is practical epistemy (Muntigl, Choi, 2010) or social

\footnotetext{
' solveigablumberga@gmail.com
}

epistemology (Jacobson, 2007). The theory of social epistemology establishes necessity in research of knowledge transfer and exchange (Jacobson, 2007) to explore trust in and reliance on epistemic authority (Asmuß, Svennevig, 2009: Kruglanski, 1989; Kruglanski et al., 2005). From a wider point of view, research into epistemic authority of the professor means exploration of students' epistemological views in relation to acquisition, transmission and acceptance of knowledge and its effects on the functioning of students in the academic environment (Heritage, Raymond, 2005; Mugny et al., 2006; Quiamzade et al., 2009).

The concept of epistemic authority is used in the research study (Asmuß, Svennevig, 2009; Glenn, LeBaron, 2011; Guimond, 2001; Hepburn, 2006; Jacobson, 2007; Kruglanski et al., 2005; Raviv et al., 1993). Research into epistemic authority is related to the degree of reliance on epistemic authority (Kruglanski, 1989; Kruglanski et al., 2005; Raviv et al., 1993). In the professional environment of institutions of higher education, the status of the professor determines their formal authority, but the way students perceive the professor's formal authority involves their functional authority, especially such sources thereof as competence, experience, and management skills which either supplement or contradict formal authority.

To perform empirical research of student-perceived epistemic authority of university professors, the author created a content model for epistemic authority of university professors (see Figure 1), based on previous analysis of various sources. In her research into student-perceived epistemic authority of university professors, the author relies on the concept that the source of information (i.e., the professor) may become an epistemic authority only as far as students believe the professor to have properties that make him/her such authority (Kruglanski et al., 2005; Raviv et al., 1993; Schommer-Aikins, 2004).

For professors to be able to strengthen and use their authority of an expert, they need to become epistemic authorities. The study includes two principal questions: 1) what is epistemic authority in a specific area of knowledge; 2) what is the basic justification for the choice of the epistemic authority (Raviv, Bar-Tal, Raviv, Peleg, 1990)

Since authority is realised in communication, the model involves the concept of pedagogue's plan of interaction which includes the intra (intraindividual personality attribution) - inter (interindividual personality attribution) meta (metaindividual attribution) plan and the emotional needs, cognitive - informative and behaviour components included in each plan (Petrovskij, 1984). Epistemic authority assessed by the current students, i.e., the actual interaction, is analysed in the Inter - plan. Professors' authority assessed by graduates, i.e., the remote interaction, is analysed in the Meta - plan. The idea of interpersonal influence also in remote interaction, which is included in the personality systemic - procedural model, has been used 
in the creation of the content of professors' epistemic authority (Vorobjov, 1997).

An essential component of a professor's epistemic authority is reasons for reliance on the authority (Bar-Tal et al., 1991) which explain the factors underlying the opting for the authority. The concept of reliance includes assessment of reasons which, in fact, demonstrate the degree of the professor's authority. The necessity for research into the reliance factors (reasons) is revealed in studies into conceptualisation of informative power (Baldwin, Kiviniemi, Snyder, 2009); process of mutual creation and application of knowledge by the student and the professor (Jillapalli, Wilcox, 2010).

The content of epistemic authority of a university professor (see Figure 1) includes four dimensions: first dimension: student- and graduate-perceived epistemic authority of the professor; the second dimension is the reasons for reliance on epistemic authority of the professor; the third dimension is the justification for reliance on the professor's epistemic authority; the fourth dimension, which is the dimension of time, is perception of the professor's epistemic authority in actual interaction (perception by students) and remote interaction (perception by graduates).

The methodology for research into epistemic authority includes three interrelated surveys: First - Epistemic Authority Scale (Raviv et al., 1993), which was used to find out the degree of perceived epistemic authority of one professor selected by students and graduates through assessment of four components (see Figure 1) between 1 (disagree entirely) and 6 (agree entirely).

Second - Reliance Question (Raviv et al., 1993) which was used to find out the reasons for reliance of the students and graduates on the epistemic authority of the same professor through rating of 12 reasons (i.e., factors) between 1 (does not correspond) and 6 (corresponds) (see Figure 1). Third - Reasoning Questionnaire (Raviv et al., 1993). This survey was used to determine the degree of influence of the reason for reliance (based on which of the reasons is or is not acknowledged as reasoning for reliance on the information (knowledge) provided by the professor, i.e., epistemic authority. The degrees were differentiated in all surveys: 1 - 2 points - low degree; $3-4$ points - medium degree; $5-6$ points - high degree.

The study sample consisted of students $(N=152)$ of various institutions of higher education in Riga (Latvia): social area $\mathrm{N}=51$; the humanities $\mathrm{N}=50$; the sciences $\mathrm{N}=51$; graduates $(\mathrm{N}=210)$ : social area $\mathrm{N}=58$; the humanities $\mathrm{N}=86$; the sciences $\mathrm{N}=66$. The survey was conducted electronically, i.e., the questionnaire was published on a website, and e-mail messages were sent out to students and graduates to invite them to take part in the survey. The age of the respondents varied between 18 and 25 (students) and between 18 and 35 (graduates).

\section{Results}

The credibility of the results of the epistemic authority surveys was verified using the Cronbach's Alpha method. The Cronbach's Alpha results were the following: .72 in the student sample $(\mathrm{N}=152) ; .82$ in the graduate sample $(\mathrm{N}=210)$. The Cronbach's Alpha for the reasons for reliance was .87 in student sample $(\mathrm{N}=152) ; .88$ in the graduate sample $(\mathrm{N}=210)$. The Cronbach's Alpha for the reasoning for reliance was .82 in the student sample $(\mathrm{N}=152) ; .83$ in the graduate sample $(\mathrm{N}=210)$. In a similar study (Raviv et al., 1993), the Cronbach's Alpha was $>.91>.96$. Consequently, the Cronbach's Alpha for the research study conducted by the author was sufficiently high to believe that the surveys were appropriate for studying perceived epistemic authority in the cultural environment of Latvia.

Results of the descriptive statistics for the assessment of epistemic authority and its components - the indicators of the central tendency: the mean (M) and the standard deviation ( $\operatorname{Sin}$ the student and graduate samples are summarized in Table 1 (see Table 1). The obtained results show the degree and content of student- and graduateperceived epistemic authority of university professors.

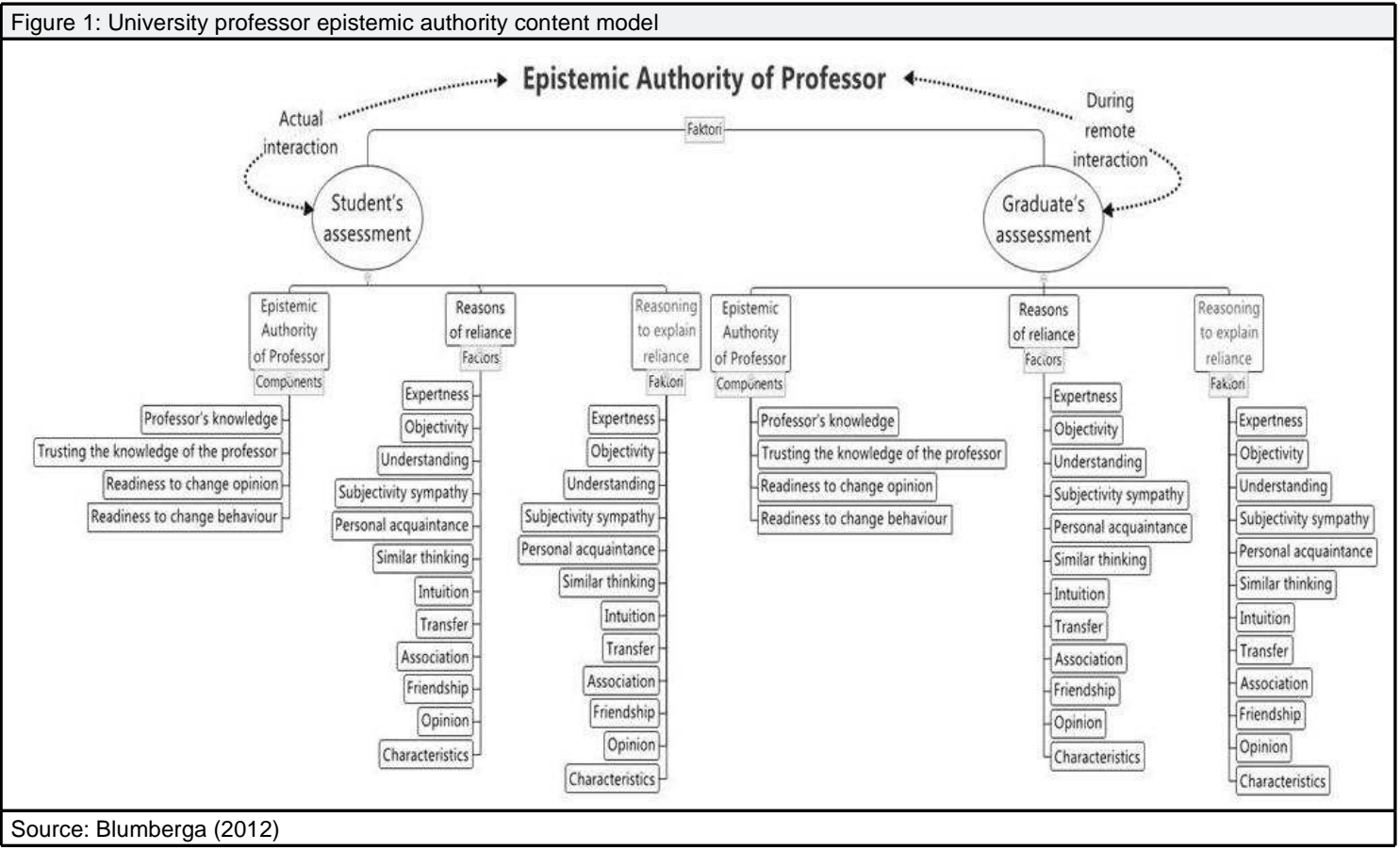




\begin{tabular}{|c|c|c|c|c|}
\hline \multirow[t]{2}{*}{ Sample } & \multicolumn{2}{|c|}{ Srudents } & \multicolumn{2}{|c|}{ Graduates } \\
\hline & \multicolumn{2}{|c|}{ Sample $(\mathrm{N}=152)$} & \multicolumn{2}{|c|}{ Sample $(\mathrm{N}=210)$} \\
\hline Statistical indicator & M & $\mathrm{S}$ & $\mathrm{M}$ & $\mathrm{S}$ \\
\hline Professor's knowledge & 5.27 & .73 & 5.18 & .84 \\
\hline $\begin{array}{l}\text { Trusting the knowledge of } \\
\text { the associate professor }\end{array}$ & 4.49 & .93 & 4.55 & .98 \\
\hline $\begin{array}{l}\text { Student's readiness to } \\
\text { change his/her opinion }\end{array}$ & 4.01 & .98 & 3.76 & 1.01 \\
\hline $\begin{array}{l}\text { Student's readiness to } \\
\text { change his/her behaviour }\end{array}$ & 3.22 & .68 & 3.09 & .64 \\
\hline Epistemic authority overall & 4.33 & .56 & 4.25 & .66 \\
\hline Source: Blumberga (2012) & & & & \\
\hline
\end{tabular}

The assessment of the knowledge component suggests a high level of professors' epistemic authority, trust in knowledge - a medium high level of epistemic authority, readiness to change opinion - a medium high level of epistemic authority in the student sample and a medium level of epistemic authority in the graduate sample; the assessment of readiness to change the behaviour suggests a medium level of epistemic authority.

A comparison of the results obtained in the student and graduate samples and those obtained during the original study (Raviv et al., 1993, p. 130) leads to a conclusion that the results are similar in both studies. Just like in the original study (Raviv et al., 1993), a tendency observed in the study conducted by the author is: higher ratings for the cognitive aspect (knowledge) and the cognitively emotional aspect (trust in knowledge) of epistemic authority, and the lowest rating for the cognitive - behavioural aspect (readiness to change behaviour).

The assessment given for the reasons for reliance on epistemic authority showed that the main reasons why students acknowledge the professor an epistemic authority are that the professor holds opinions the students and graduates accept (acceptance of opinion); the professor's ability to be an expert, i.e., to be knowledgeable and experienced in their professional area $M=5.56 ; M=5.45$ ), and the professor's impartiality in their assessments $(M=5.09 ; M=5.01)$. Consequently, according to the definition of reasons for reliance given by Raviv et al. (1993), the students and graduates surveyed within the study conducted by the author perceive the professor as an epistemic authority to the highest degree in the factors of acceptance of opinion, expertise, and impartiality.
The ratings given by the students and graduates for reasons for reliance shows how much the professor is or is not acknowledged as an authority; this affects reliance on the information provided by the professor and is proven by the results of the survey to find out the reasoning to explain reliance (see Table 2).

Consequently (see Table 2), the professor's expertness (i.e., ability to be an expert) has the highest degree of influence on reliance of students and graduates on the professor's epistemic authority; it can be defined as a high indicator of reasoning to explain reliance (Raviv et al., 1993). Medium ratings, with a tendency to higher results in both samples and groups of study areas, have been provided for professor's impartiality; characteristics (the professor has character traits essential to students). A similar tendency can be observed also in the ratings provided for similarity of opinions between students and the professor (as reason for reliance); lower reliance reason ratings, but still within the range of medium degree (see Table 2), were : professor's understanding of students' needs (understanding), similar thinking between the professor and the students (similar thinking), transfer-related reliance reasons - influence of other important persons (association, friendship). In most cases (see Table 2), there were low $(M<3.0)$ ratings for whether the student or the graduate believes he/she knows the professor personally. Comparatively low ratings $(\mathrm{M}=2.59$ - $M=3.48$ ) were given for knowing personally as a reason for reliance, and this explains low ratings for reasoning to explain reliance.

An evaluation of differences between the ratings provided for the epistemic authority and reliance on the epistemic authority in actual and remote interaction in the study groups (Mann-Whitney Test) lead to a conclusion that essential differences between the ratings provided by students and graduates for their perceived epistemic authority of professors, reasons for reliance and the reasoning to explain reliance cannot be seen frequently, but highlight the role of the specifics of the study areas as well as differences in perception of the professor's epistemic authority in actual and remote interaction between the student and the professor. For example, there was as significant difference $(p<.05)$ in the rating provided for readiness to change opinion. Students have a higher degree of readiness to change their opinion under the influence of the professor as an epistemic authority than graduates.

The factor analysis primary correlation matrix consisted of the following variables: 4 components of epistemic authority;

\begin{tabular}{|c|c|c|c|c|c|c|c|c|c|}
\hline \multirow[t]{2}{*}{ No } & \multirow[t]{2}{*}{ Reason for reliance /student sample (S); graduate sample (G) } & \multicolumn{2}{|c|}{ Sample } & \multicolumn{2}{|c|}{ Social area } & \multicolumn{2}{|c|}{ The Humanities } & \multicolumn{2}{|c|}{ The Sciences } \\
\hline & & S & G & S & G & S & G & S & G \\
\hline 1 & Expertness & 5,21 & 5,27 & 5,12 & 5,33 & 5,26 & 5,31 & 5,25 & 5,15 \\
\hline 2 & Objectivity & 4,7 & 4,94 & 4,82 & 4,91 & 4,62 & 5,01 & 4,67 & 4,86 \\
\hline 3 & Understanding & 4,19 & 3,89 & 4,22 & 4,12 & 4,38 & 3,91 & 3,98 & 3,67 \\
\hline 4 & Subjectivity sympathy & 4,08 & 4,03 & 4,08 & 4,19 & 4,22 & 4,13 & 3,94 & 3,76 \\
\hline 5 & Personal acquaintance & 2,84 & 3,09 & 2,8 & 3,29 & 3,16 & 2,99 & 2,55 & 3,03 \\
\hline 6 & Similar thinking & 3,99 & 3,87 & 4,16 & 3,84 & 4,12 & 3,99 & 3,69 & 3,74 \\
\hline 7 & Intuition & 4,45 & 4,35 & 4,53 & 4,47 & 4,48 & 4,3 & 4,35 & 4,32 \\
\hline 8 & Transfer & 3,38 & 3,2 & 3,43 & 3,33 & 3,7 & 3,24 & 3,02 & 3,02 \\
\hline 9 & Association & 3,37 & 2,92 & 3,55 & 3,26 & 3,5 & 2,76 & 3,06 & 2,83 \\
\hline 10 & Friendship & 3,53 & 3,27 & 3,59 & 3,4 & 3,74 & 3,27 & 3,25 & 3,17 \\
\hline 11 & Opinion & 4,43 & 4,45 & 4,27 & 4,36 & 4,54 & 4,53 & 4,47 & 4,42 \\
\hline 12 & Characteristics & 4,57 & 4,44 & 4,67 & 4,45 & 4,52 & 4,55 & 4,53 & 4,3 \\
\hline
\end{tabular}


reliance questions (i.e., 12 reasons for reliance) and 12 justifications for reliance. The factor analysis was performed using the Extraction Method: Principal Component Analysis. Rotation Method: Varimax with Kaiser Normalization.

Analysis of the factor matrix, 3 newly developed factor models could be highlighted in both samples (students and graduates): cognitive - emotional aspect of the professor's epistemic authority (see Table 3 ) 3 . which revealed the importance of the knowledge, experience and impartiality of the professor; transfer which revealed the role of attitudes of other reference individuals towards the professor in student- and graduate-perceived epistemic authority of the professor; similarities between the professor and the student which revealed the role of similar thinking and personal traits in making decisions regarding reliance on the professor as an essential source of information. The factor models include only the factors with value $>0.4$, as such value sufficiently well explains the initial variation of the variable.

Consequently, for students to perceive the professor as an essential source of information, trust the information provided by him/her, and develop readiness to change opinion, it is essential that students acknowledge the following competences of the professor as reasons for reliance: ability to be an expert in their area and ability to be impartial (objective). In such context, impartiality is more important to students, and this suggests that, in remote interaction, it becomes a more essential factor of the professor's epistemic authority.

\section{Conclusion}

The results obtained for student- and graduate-perceived epistemic authority of professors related to the concept that live presence of the professor (i.e., actual interaction) may intensify the perceived authority, which researchers position as social-context-determined and communicative behaviour determinant (Tremayne, Chen, Figur, Huang, 2008). In the research study conducted by the author, higher ratings were given for epistemic authority of professors in the student sample (actual interaction). The variations in the results can also be explained by the individual qualities of the respondents: individual states of motivation, individual learning experience (Ricco, Schuyten, Pierce, Medinilla, 2010; Schommer-Aikins, 2004; Yariv, 2009).

The results obtained by the author during the study to obtain epistemic authority ratings show a successful implementation of professors' authority dimension „source of knowledge or assumed truth” (Pace, Hemming, 2007), which is an essential feature of an epistemic authority (Kruglanski et al., 2005; Qiuamzade et al., 2009).

During the study, results have been obtained which show high levels of perceived epistemic authority of professors in the knowledge component; medium high levels in the knowledge trust component, medium levels of role of epistemic authority in the component of readiness of students and graduates to change their behaviour and the component of readiness to change behaviour. Further studies need to be conducted to find out what factors determine comparatively lower indicators in the component of students' readiness to change their behaviour. The results obtained for reasoning to explain reliance, in relation to professors' expertness (cognitive aspect) and impartiality (cognitively emotional aspect) confirm the conclusion that, even though authority is initially based on the formal position, its acceptance is influenced by the professional competence and experience.

The content of the professor's epistemic authority develops and manifests in actual and remote interaction between the professor and the student. The content of epistemic authority of a university professor includes three dimensions of meaning: student-perceived authority of the professor, reasons for reliance, reasoning to explain reliance, and the fourth dimension, which is the dimension of time.

\section{REFERENCES}

1. Asmuß, B., Svennevig, J. "Meeting Talk : An Introduction." Journal of Business Communication 46 2009: 3- 22.

2. Baldwin, A., Kiviniemi, M., Snyder, M. "Subtle Source of Power: The Effect of Having an Expectation on Anticipated Interpersonal Power." The Journal of Social Psychology 149(1) 2009: 82-104.

3. Bar-Tal, D., Raviv, A., Raviv, A., Brosh, M. "Perception of epistemic authority and attribution for its choice as a function of knowledge area and age." European Journal of Social Psychology v21 1991: 477- 492.

4. Chiang, S-Y. "Personal power and positional power in a powerfull. 'l': a discourse analysis of doctoral dissertation supervision." Discourse \& Communication v3 no3 2009: 255-271.

5. Glenn, P., LeBaron, C. "Epistemic authority in employment interviews: Glancing, pointing, touching." Discourse \& Communication 5(1) 2011: 3-22.

6. Guimond, S. Epistemic authorities in higher education: The relative influence of peers, faculty and courses on attitude formation and change. In F. Butera \& G. Mugny (Eds.) Social influence in social reality, Seattle: Hogrefe \& Huber, 2001: 211-223.

7. Hepburn, A. "Getting Closer at a Distance : Theory and the Contingencies of Practice." Theory Psychology v16 2006 : 327342.

8. Heritage, J., Raymond, G. "The Terms of Agreement: Indexing Epistemic Authority and Subordination in Talk-in-Interaction." Social Psychology Quarterly v68 no1 2005: 15- 38.

9. Jacobson, N. "Social Epistemology : Theory for the 'Fourth Wave' of Knowledge Transfer and Exchange Research." Science Communication v29 2007: 116- 127

10. Jillapalli, K., Wilcox, B. "Professor Brand Advocacy: Do Brand Relationships Matter?" Journal of Marketing Education v32 2010: 328- 340.

11. Kruglanski, A. Lay epistemics and human knowledge: Cognitive and motivational bases. New York: Plenum, 1989.

12. Kruglanski, A., Raviv, A., Bar-Tal, D., Raviv, A., Sharvit, K., Ellis, S., Bar, R., Pierro, A., Mannetti, L. "Says who? Epistemic authority

\begin{tabular}{|l|l|l|l|}
\hline Table 3: Factor model - the cognitively emotional aspect of the professor's epistemic authority \\
\hline $\begin{array}{l}\text { Initial variables } \\
\text { (student sample N=152) }\end{array}$ & $\begin{array}{l}\text { Factor } \\
\text { value }\end{array}$ & $\begin{array}{l}\text { Initial variables } \\
\text { (graduate sample N=210) }\end{array}$ & $\begin{array}{l}\text { Factor } \\
\text { value }\end{array}$ \\
\hline $\begin{array}{l}\text { The associate professor is an expert: well-educated or } \\
\text { experienced (reason for reliance) }\end{array}$ & .600 & $\begin{array}{l}\text { The associate professor was an expert: well-educated } \\
\text { or experienced }\end{array}$ & .667 \\
\hline $\begin{array}{l}\text { The associate professor is objective (impartial) in } \\
\text { his/her evaluations (reason for reliance) }\end{array}$ & .557 & $\begin{array}{l}\text { The associate professor was objective (impartial) in } \\
\text { his/her evaluations (reason for reliance) }\end{array}$ & .710 \\
\hline Level of knowledge (component of epistemic authority) & .801 & Level of knowledge (component of epistemic authority) & .791 \\
\hline Trust in knowledge (component of epistemic authority) & .769 & Trust in knowledge (component of epistemic authority) & .775 \\
\hline $\begin{array}{l}\text { Readiness to change opinion (component of epistemic } \\
\text { authority) }\end{array}$ & .434 & $\begin{array}{l}\text { Readiness to change opinion (component of epistemic } \\
\text { authority) }\end{array}$ & .459 \\
\hline Source: Blumberga (2012) & & \\
\hline
\end{tabular}


effects in social judgment." In M. P. Zanna (Ed.). Advances in experimental social psychology vol. 37 2005: 346-392.

13. Miettinen, R., Virkkunen, J. "Epistemic Objects, Artefacts and Organizational Change." Organization v12 2005: 437- 456.

14. Mugny, G., Chatard, A., Quiamzade A. "The Social Transmission of Knowledge at the University: Teaching Style and Epistemic Dependence" European Journal of Psychology of Education v21 no4 2006: 413- 427.

15. Muntigl, P., Choi, K. "Not remembering as a practical epistemic resource in couples therapy." Discourse Studies v12 no3 2010: 331-356.

16. Quiamzade, A., Mugny, G., Chatard, A. "When teaching style matches students' epistemic (in) dependence: The moderating effect of perceived epistemic gap." European Journal of Psychology of Education vXXIV no3 2009:361-371.

17. Pace, J., Hemmings, A. Understanding Classroom Authority: Theory, Ideology, and Research on Practice, Review of Education Research vol.77 no1 2007: 4-27.

18. Patchen, T., Crawford, T. "From Gardeners to Tour Guides: The Epistemological Struggle Revealed in Teacher-Generated Metaphors of Teaching." Journal of Teacher Education v62 2011: 286- 298

19. Petrovskij, A. Litschnostj. Dejatelnostj. Kollektiv. Moskva: Politizdat, 1984.

20. Pounder, S. "Full-range Classroom Leadership: Implications for the Cross-organizational and Cross-cultural Applicability of the Transformational- transactional Paradigm." Leadership v4 2008: p115- 135.

21. Raviv, A., Bar-Tal, D., Raviv, A., Peleg, D. "Perception of epistemic authorities by children and adolescents." Journal of Youth and Adolescence v19 1990: 495- 510.

22. Raviv, A., Bar-Tal, D., Raviv, A., Abin, R. "Measuring epistemic authority: studies of politicians and professors." European Journal of Personality v7 1993: 119-138.

23. Ricco, R., Schuyten Pierce, S., Medinilla, C. "Epistemic Beliefs and Achievement Motivation in Early Adolescence." The Journal of Early Adolescence v30 no2 2010: 305- 340.

24. Rupp, E. "An employee-centered model of organizational justice and social responsibility." Organizational Psychology Review v1 2011: 72- 94

25. Schommer-Aikins, M. "Explaining the epistemological belief system: Introducing the embedded systemic model and coordinated research approach." Educational Psychologist 39(1) 2004: 19-29.

26. Subramaniam, B. "Imperfect Oracle: The Epistemic and Moral Authority of Science." Contemporary Sociology: A Journal of Reviews v39 no6 2010: 687- 688.

27. Tremayne, M., Chen, X., Figur, N., Huang, J. "Perceived authority and communication channel: Experiments with instant messaging." Social Science Computer Review 26(2) 2008:178-189.

28. Vorobjov, A. Personologija: problemi soderzjanija i aktivnostji litschnostji. Daugavpils: University of Daugavpils, 1997.

29. Ward, L. and Parr, J. "Authority, Volunteerism, and Sustainability: Creating and Sustaining an Online Community through Teacher Leadership." Leadership and Policy in Schools 5 2006: 109- 129.

30. Yariv, E. "Students' Attitudes on the Boundaries of Teachers' Authority." School Psychology International 2009: 30- 92. 